\title{
Inter-daily variability of a strong thermally-driven wind system over the Atacama Desert of South America: synoptic forcing and short-term predictability using the GFS global model
}

\author{
Martín Jacques-Coper • Mark Falvey • \\ Ricardo C. Muñoz
}

Received: 6 February 2014 / Accepted: 16 July 2014 / Published online: 30 July 2014

(C) Springer-Verlag Wien 2014

\begin{abstract}
Crucial aspects of a strong thermally-driven wind system in the Atacama Desert in northern Chile during the extended austral winter season (May-September) are studied using 2 years of measurement data from the Sierra Gorda 80m meteorological mast (SGO, 22 $56^{\circ} 24^{\prime \prime} \mathrm{S} ; 69^{\circ} 7^{\prime} 58^{\prime \prime} \mathrm{W}$, 2,069 $\mathrm{m}$ above sea level (a.s.1.)). Daily cycles of atmospheric variables reveal a diurnal (nocturnal) regime, with northwesterly (easterly) flow and maximum mean wind speed of $8 \mathrm{~m} / \mathrm{s}$ $(13 \mathrm{~m} / \mathrm{s})$ on average. These distinct regimes are caused by pronounced topographic conditions and the diurnal cycle of the local radiative balance. Wind speed extreme events of each regime are negatively correlated at the inter-daily time scale: High diurnal wind speed values are usually observed together with low nocturnal wind speed values and vice versa. The associated synoptic conditions indicate that upper-level troughs at the coastline of southwestern South America reinforce the diurnal northwesterly wind, whereas mean undisturbed upper-level conditions favor the development of the nocturnal easterly flow. We analyze the skill of the numerical weather model Global Forecast System (GFS) in predicting wind speed at SGO. Although forecasted wind speeds at $800 \mathrm{hPa}$ do show the diurnal and nocturnal phases, observations at $80 \mathrm{~m}$ are strongly underestimated by the model. This causes a pronounced daily cycle of root-mean-squared error (RMSE) and bias in the forecasts. After applying a simple Model Output Statistics (MOS) post-processing, we achieve a good representation of the wind speed intra-daily and inter-
\end{abstract}

\footnotetext{
M. Jacques-Coper $(\triangle)$

Oeschger Centre for Climate Change Research and Institute of

Geography, University of Bern, Hallerstrasse 12, 3012 Bern,

Switzerland

e-mail: jacques@giub.unibe.ch

M. Falvey $\cdot$ R. C. Muñoz

Departamento de Geofísica, Universidad de Chile,

Av. Blanco Encalada, 2002 Santiago, Chile
}

daily variability, a first step toward reducing the uncertainties related to potential wind energy projects in the region.

\section{Introduction}

The Atacama Desert in northern Chile has been widely described as the driest place of the world (e.g., Garreaud et al. 2010). Its extreme surface aridity, the large-scale atmospheric stability due to its subtropical location, and the regional topographic gradient between the towering Andes Cordillera $(>6,000 \mathrm{~m})$ and the Pacific Ocean over a distance of less than $300 \mathrm{~km}$ support the local existence of strong thermally driven wind systems. They have been qualitatively described by Schmidt (1999) and measured during short-term field campaigns by Rutllant and Ulriksen (1979) and Rutllant et al. (2003). Recently, Muñoz et al. (2013) characterized these systems based on 2 years of multilevel measurements from three 80-m meteorological masts. They assessed the regional variability of winds, the local co-variability of near-surface wind and temperature vertical profiles, and presented hourly average nighttime wind speed maxima of up to $20 \mathrm{~m} / \mathrm{s}$ during the cold season, peaking between 20 and $60 \mathrm{~m}$ above ground level. However, the large-scale factors controlling the pronounced inter-daily variability of these winds have not yet been thoroughly examined, and this constitutes the first main motivation for the present study.

The second reason for this research is provided by the Chilean energy context. At national level, energy source diversification is an imperative task for the country, mainly due to problems related to fossil fuel availability and the natural variability of water resources. Some studies suggest that the renewable share of the whole country's electric system could be as high as $25 \%$ by 2024 (Hall et al. 2009). By then, at global scale, wind energy will surely play a crucial role in satisfying the energy demand of sustainable societies. In spite 
of huge reported renewable energy resources in the North of Chile (e.g., solar, wind, geothermal), the regional power system $(\sim 4,400 \mathrm{MW})$ feeding the large power-demanding mining industry, the most important economic activity of the country, relies almost entirely $(99.7 \%)$ on thermal power plants (Comisión Nacional de Energía de Chile (CNE) 2011). Therefore, the wind energy potential of this region is of special interest. In particular, skillful short-term wind and wind power predictability (up to $72 \mathrm{~h}$ ) are crucial for future wind energy projects (von Bremen et al. 2007). In this context, a cooperation agreement between the Chilean Energy Ministry and the German government launched an assessment program of public sites showing high wind potential and installed twenty 20 $\mathrm{m}$ meteorological towers and four 80-m masts in the Atacama Desert region (Meyer 2011).

In this paper, we use the data measured at the Sierra Gorda 80-m mast (SGO, 22 $2^{\circ} 56^{\prime} 24^{\prime \prime} \mathrm{S} ; 69^{\circ} 7^{\prime} 58^{\prime \prime} \mathrm{W}, 2,069 \mathrm{~m}$ above sea level (a.s.l.), reporting since April 2010) in order to study the large-scale forcing that determines the inter-daily variability of the diurnal and nocturnal regimes of this local wind system. In addition, as a first step toward assessing the predictability of wind speed within thermally driven wind systems over the Atacama Desert, we explore the skill of the Global Forecast System (GFS) model in predicting wind speed at SGO. Finally, we apply a MOS post-processing technique in order to improve the raw outputs from the model with respect to the observations. Although the spatial resolution of the global model chosen (T574 spectral horizontal resolution for the first 7.5 forecasted days, i.e., $\sim 27 \mathrm{~km}$ ) is not appropriate for resolving wind systems over complex terrain, we selected this approach in order to quantify the accuracy that can be achieved by using an operational and freely available product and a simple statistical correction method, nondemanding in terms of computational intensity. In this respect, the results obtained in this study can be used as a benchmark for future regional modeling efforts with higher spatial resolution.

The article is structured as follows: Sect. 2 introduces the study area, discusses briefly the main aspects that determine the particular local wind systems, and presents the data. The synoptic forcing of wind observations is described in Sect. 3. In Sect. 4, we analyze the forecast skill of GFS, focusing on wind intensity and direction, and then propose the MOS empirical adjustment methodology to improve the wind speed forecast at SGO. Finally, Sect. 5 presents a summary of the work and our conclusions.

\section{Study area, regional wind, and data}

\subsection{Study site}

As shown in Fig. 1, our study site is located at the mouth of a transverse valley, the Arriero's Creek. This creek, of east-west orientation, is flanked by peaks in the $3,000-4,000 \mathrm{~m}$ a.s.1. range. In a more regional context, the Andes Cordillera, with elevations exceeding $6,000 \mathrm{~m}$, lies approximately $250 \mathrm{~km}$ to the east of the Pacific Ocean. This regional geographical configuration determines a steep west-east altitudinal gradient, interrupted by the Intermediate Depression. This sets up conditions that lead to intense nocturnal topography-following flows, generated by horizontal temperature (and thus pressure) gradients induced by the differential heating and cooling of the complex terrain, as described by Muñoz et al. (2013). In this region, apart from some summer convective events coming from the Altiplano, there is virtually no precipitation. Thus, solar radiation reaches the surface through clear skies and a very dry atmosphere, warming it vigorously from sunrise until sunset, when the surface energy balance changes sign, long-wave radiative losses dominate, and a rapid surface cooling takes place. Since sensible heat flux plays a primary role in the surface energy balance of the Atacama Desert, the diurnal thermal amplitude near the surface, and the intensity of the low-level circulation induced by it and the steep orography are usually large.

Whiteman (2000) identifies four main components of a mountain wind system, namely slope winds, along-valley winds, cross-valley winds, and mountain-plain winds, depending on whether the near-surface temperature variations driving the flow occur along a slope, along a valley axis, across valley sidewalls, or between a mountain and a nearby plain, respectively. Real cases like that studied here may include all of these forcing mechanisms in various degrees, and distinguishing the relative roles played by each one is left for mesoscale modeling works. All of them, however, can be synoptically modulated by large-scale pressure gradients, which is the main aspect addressed here. For this reason, as in Muñoz et al. (2013), we will use the term drainage winds to refer to the nocturnal flows described in this paper.

\subsection{Regional wind}

Regional-scale synoptic winds can superpose on local systems in various ways and may reinforce the intensity of these systems or even suppress their development completely. More generally, synoptic circulation features can disturb the climatological large-scale atmospheric circulation pattern over northern Chile, which is partly determined by the semipermanent presence of the Southeastern Pacific Anticyclone (SEPA), located below the subsidence branch of the Hadley Cell (Garreaud and Falvey 2009; Muñoz and Garreaud 2005; Rahn et al. 2011). The SEPA defines a pressure field that decreases from its center toward the coast. During austral winter (JJA), its center is shifted to the North with respect to the climatology, at approximately $27^{\circ} \mathrm{S}, 90^{\circ} \mathrm{W}$ (Fig. 2). In accordance with the position of the SEPA, the southerly coastal winds in northern Chile reach their maximum intensity 
Fig. 1 Topographic map of the area surrounding the Sierra Gorda metmast (SGO) in the Chilean Norte Grande region. Terrain contours every $500 \mathrm{~m}$. The map on the top-left corner indicates the location of the study area within South America

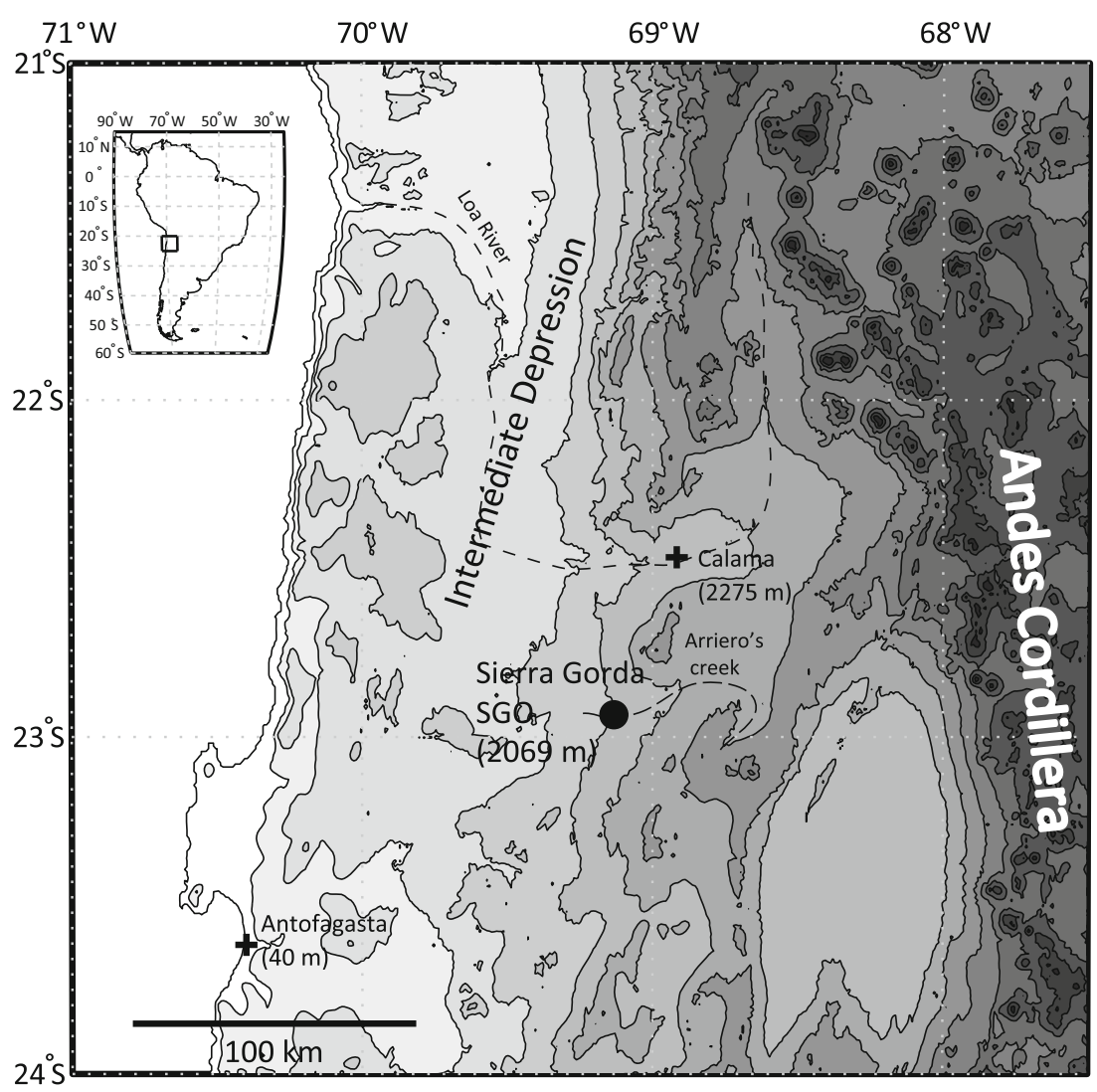

during this season. However, the coastal wind occasionally reverses its direction, a phenomenon that is usually linked to the culmination of sub-synoptic coastal lows (once or twice per month) associated with the passage of synoptic pressure perturbations further south (Garreaud and Rutllant 2003). Upper-level winds along $30^{\circ} \mathrm{S}$, on the other hand, have mainly eastward direction, exhibiting jet speeds over $30 \mathrm{~m} / \mathrm{s}$ at heights of about $10 \mathrm{~km}$. The Andes Cordillera, with altitudes over 5,000 and even $6,000 \mathrm{~m}$ to the north of $35^{\circ} \mathrm{S}$, imposes a mechanical blocking to the westerly flow in the free atmosphere, deflecting it toward the South (Garreaud 2009; Kalthoff et al. 2002; Rutllant et al. 2013). This northerly jet extends over the Intermediate Depression, also known as the Central Valley, which is the north-south oriented plateau situated between the Andes and the coastal ranges (Fig. 2), and can even reach the coastline.

\subsection{Data}

Observations were registered by the SGO meteorological mast $\left(22^{\circ} 56^{\prime} 24^{\prime \prime} \mathrm{S} ; 69^{\circ} 7^{\prime} 58^{\prime \prime} \mathrm{W}, 2,069 \mathrm{~m}\right.$ a.s.l.) in the Atacama Desert (Fig. 1). The mean surface pressure recorded during the analyzed period was $795 \mathrm{hPa}$. The tower has instruments installed at various heights that register the following variables in the form of 10-min averages: air temperature $(2,10$, and $40 \mathrm{~m})$, relative humidity $(2 \mathrm{~m})$, wind speed $(20,40,60$, and $80 \mathrm{~m})$, wind direction (60 $\mathrm{m})$, atmospheric pressure $(5 \mathrm{~m})$, and net radiation $(5 \mathrm{~m})$. With the aim of focusing on the period when highest nocturnal wind speeds are observed at the site, as described in Muñoz et al. (2013), we restrict the analysis in this study to the extended austral winter period, namely May

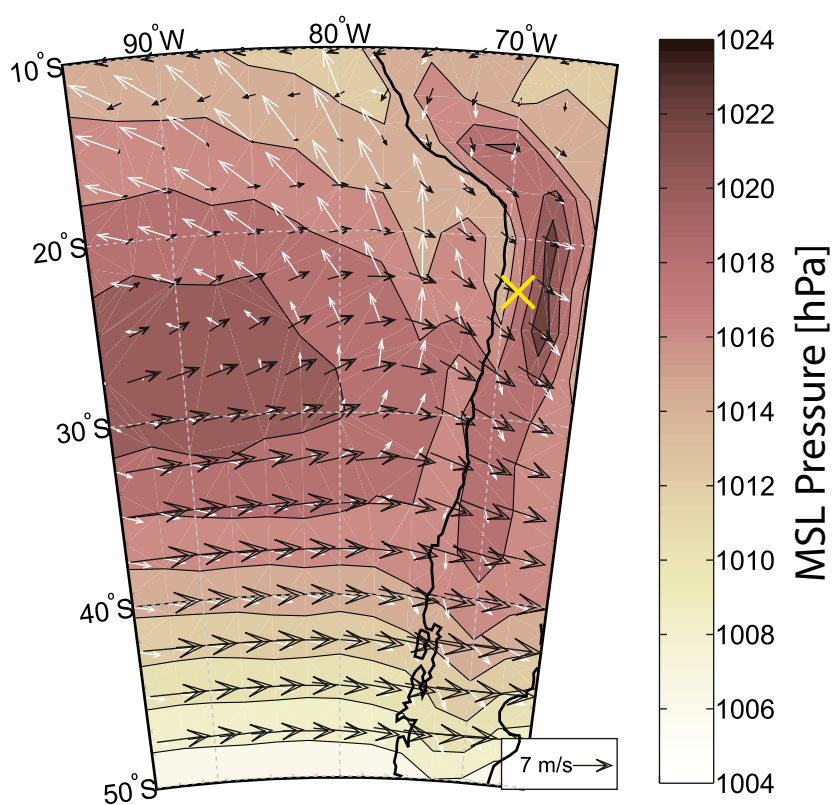

Fig. 2 July mean NNR fields (1968-1996) of SLP (hPa) (filled contours), surface wind (white vectors), and 700-hPa wind (black vectors). A reference vector is shown in the lower right corner. The yellow cross indicates the location of the SGO metmast 
to September (MJJAS), of those years with publicly available data: 2010 and 2011 (a total of 306 days). Regional circulation was assessed by means of the NCEP-NCAR reanalysis I (NNR, Kalnay et al. 1996). GFS model data is described in Sect. 4.

\section{Wind daily cycle and synoptic forcing}

\subsection{Diurnal and nocturnal regimes}

We describe briefly some aspects of the mean daily cycle of our observations. A deeper characterization and discussion on this subject can be found in Muñoz et al. (2013). Hereafter, unless otherwise specified, hours are referred to local time: $\mathrm{LT}=\mathrm{UTC}-4$. During the analyzed period, temperature records indicate a diurnal thermal amplitude of nearly $15^{\circ} \mathrm{C}$ at $2 \mathrm{~m}$ (not shown). The mean temperature increases from ca. $6^{\circ} \mathrm{C}$ at 7 a.m. (just before sunrise) to more than $21^{\circ} \mathrm{C}$ at 3 p.m. (after the maximum incident radiation at midday). At 10 and $40 \mathrm{~m}$, a smaller thermal amplitude and a delay in the detection of the highest temperature with respect to the 2-m level are observed. Between 6 p.m. (approximately sunset time) and 8 a.m., a thermal inversion develops due to surface cooling. Around 8 p.m., the atmospheric cooling rate in the lowest levels shows a significant increase, apparently linked to the development of a drainage flow, which begins at that time with an abrupt wind direction change from NW to E. Just before sunrise, the thermal inversion shows a mean temperature difference of $\sim 1.5^{\circ} \mathrm{C}$ between 2 and $40 \mathrm{~m}$.

As observed in Fig. 3, the mean diurnal wind speed and wind direction frequency cycles at SGO during MJJAS can be separated in two well-differentiated regimes: a daytime phase (1 p.m., 6 p.m.) and a nocturnal phase (8 p.m., 9 a.m.), with transition periods in-between. This definition takes into account the daily radiative cycle and the clear distinction between two different predominant wind directions: northwesterly upslope flow during the afternoon and easterly drainage flow at night. During this cold season, the largest mean wind speeds occur during the nighttime phase with mean values around $13 \mathrm{~m} / \mathrm{s}$ and peak events reaching about $20 \mathrm{~m} / \mathrm{s}$. The shapes of the vertical profiles of wind speed are also different for each phase (not shown). Within the diurnal regime, the average speed profile increases with height, with a maximum mean value of around $8 \mathrm{~m} / \mathrm{s}$ at $80 \mathrm{~m}$ just before 6 p.m. During nighttime, however, maximum speeds are generally observed at $40 \mathrm{~m}$, which is indicative of a drainage low level jet (LLJ) that peaks before sunrise approximately at 7 a.m.

\subsection{Synoptic forcing}

The inter-daily variability of wind intensity is explored for the nocturnal and diurnal regimes by means of the series formed by their corresponding daily averages, i.e., considering [1 p.m., 6 p.m.] and [8 p.m., 9 a.m.], respectively. In the following, all results are computed from the anomalies that result after detrending the daily series and extracting their annual cycles, by subtracting a least-squares linear regression and the adjusted 365.25 days harmonic, respectively. Statistical significance of correlation coefficients is determined at the $95 \%$ level, considering the effective number of degrees of freedom of the data (Bretherton et al. 1999), and is denoted by an asterisk next to the number.

As observed in Fig. 4, wind speeds at $40 \mathrm{~m}$ show a pronounced anticorrelation between the diurnal and nocturnal regimes. Since this relationship is strongest when considering the nights that directly follow the diurnal regimes $\left(r=-0.64^{*}\right.$, $r^{2}=0.41$ ), we will adopt this convention when comparing the diurnal and nocturnal regimes. In the scatterplot of Fig. 5, extreme wind speed deciles (30 maximum and 30 minimum values) from each regime reveal that days showing diurnal minima $(<4.6 \mathrm{~m} / \mathrm{s})$ correspond to subsequent high nocturnal wind speed values, between 8 and $15 \mathrm{~m} / \mathrm{s}$. The inverse relationship, however, is somewhat noisier: Minimum nocturnal values $(<6 \mathrm{~m} / \mathrm{s})$ correspond to diurnal values between 6 and $16 \mathrm{~m} / \mathrm{s}$.

With the aim of exploring the synoptic conditions associated with extreme events ( 5 and $95 \%$ percentiles of the wind speed distributions) of each regime, we form composites of daily geopotential height anomaly fields at $500 \mathrm{hPa}$ with respect to 5,400 gpm (NNR). In this way, we explore the large-scale circulation patterns in the mid-atmosphere

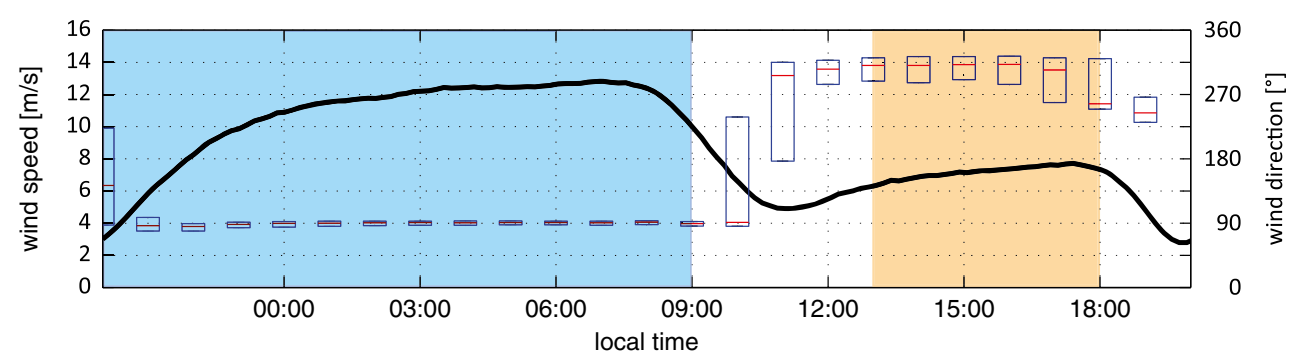

Fig. 3 Observed 2010-2011 MJJAS mean cycle of wind speed at $40 \mathrm{~m}$ (black curve) and boxplots of wind direction at $60 \mathrm{~m}$ (red marks show the medians and the edges of the box represent the 25 th and 75 th percentiles, respectively). Light blue (orange) shading indicates the nocturnal (diurnal) regimes 
Fig. 4 Mean 40-m wind speed inter-daily variability during the nocturnal and diurnal regimes for MJJAS in 2010 (upper panel) and 2011 (lower panel). Values within the extreme deciles of the wind speed distribution of each regime (30 maximum and 30 minimum events) are shown
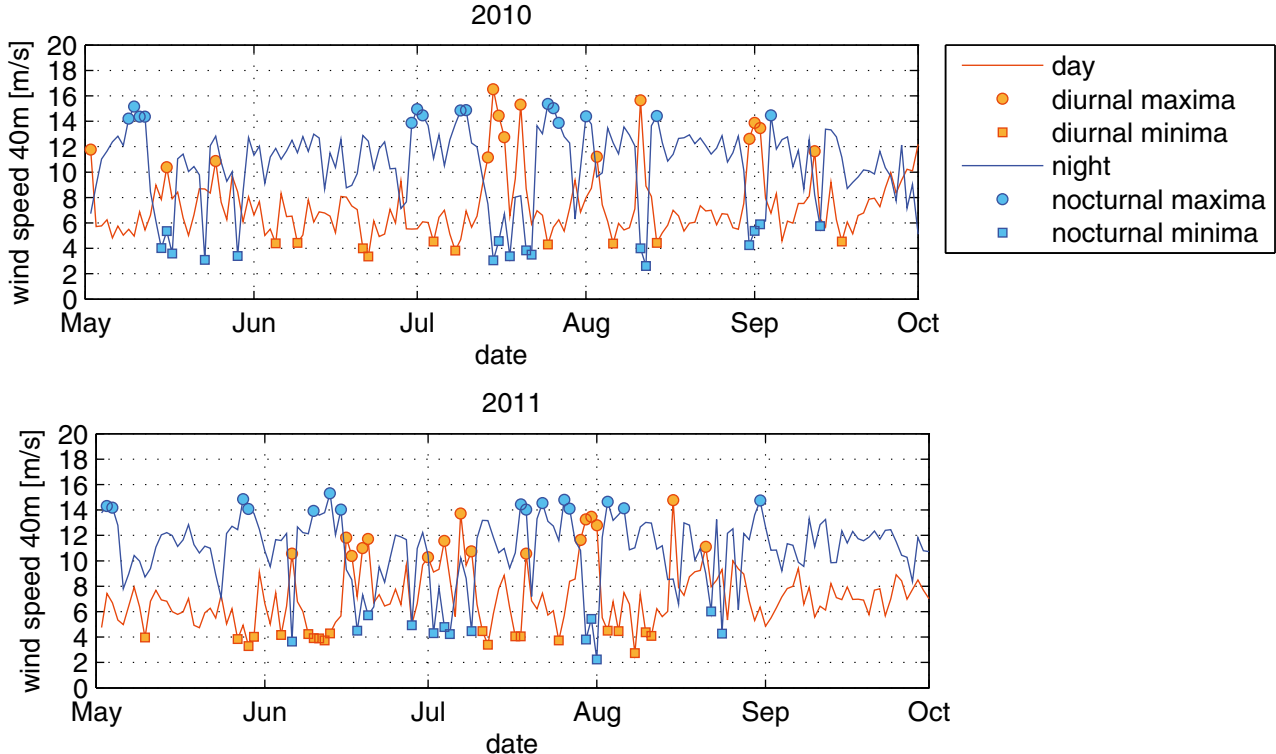

influencing the location of our meteorological mast and leading to extreme local wind values.

Figure 6a shows that diurnal wind maxima are related to an upper-level trough to the west of the continent, with northwest-southeast orientation. This configuration induces northwesterly flow in upper levels, reinforcing the characteristic near-surface diurnal wind that blows from that direction. On the other hand, days with low diurnal wind speeds (Fig. 6c) correspond to a gentle meridional geopotential height gradient over the study region, which does not induce any major synoptic perturbation of the local wind system at SGO. The nocturnal regime presents the opposite synoptic

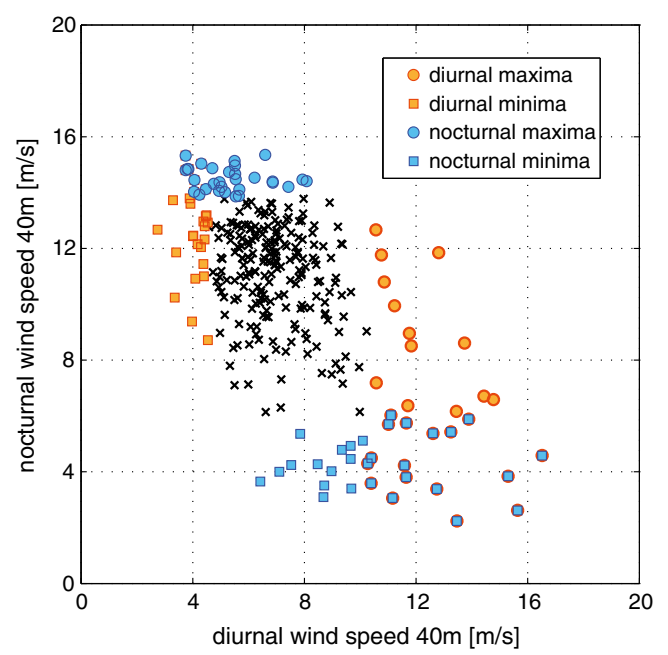

Fig. 5 Scatterplot of MJJAS mean diurnal and nocturnal daily wind speed values (black crosses; 2010-2011). Values within extreme deciles of the wind speed distribution of the diurnal (orange) and the nocturnal (blue) regime are shown: 30 maximum (circles) and 30 minimum (squares) events. The correlation coefficient between both regimes is $r=-0.63 *\left(r^{2}=0.41\right)$, the asterisk denotes statistical significance of $r$ at $95 \%$ configurations associated with extreme events: Nocturnal maxima (Fig. 6b) are consequence of a smooth meridional geopotential height gradient, which induces a modest westerly flow that does not considerably affect the local nocturnal easterly flow, and nocturnal minima (Fig. 6d) are associated with a synoptic configuration similar to that of diurnal maxima: a trough that induces westerly-northwesterly wind. This system superimposes over the nocturnal easterly flow and slows it down. The composites of the difference between fields associated to maximum and minimum wind events (Fig. 6e, f) emphasize how these configurations relate to the location of the SGO mast, showing a local cyclonic (anticyclonic) circulation anomaly associated to the difference of diurnal (nocturnal) extreme values. It is noteworthy that the negative correlation between the diurnal and nocturnal regimes not only holds for the inter-daily time scale but can also be observed at seasonal level: While the diurnal upslope flow peaks in summer, the nocturnal easterly flow is strongest during winter (Rutllant et al. 2003).

Next, we analyze the distinction of both regimes by means of the computation of correlation coefficients between selected observed atmospheric variables. Figure 7a shows the interdaily relationship between wind speed and temperature anomalies observed at 20 and $2 \mathrm{~m}$, respectively. During the diurnal regime, a significant negative correlation $\left(r=-0.60^{*}, r^{2}=\right.$ 0.36 ) can be a consequence of relatively cold advection from the Pacific Ocean by the diurnal northwesterly wind. Thus, a stronger wind during the day would result in lower measured temperatures at SGO. Contrarily, during the nocturnal regime, we just observe a negligible direct relationship between these variables $\left(r=0.12, r^{2}=0.01\right)$.

The inter-daily correlation between wind speed and water vapor mixing ratio $(w)$ is shown in Fig. $7 \mathrm{~b}$. Water vapor mixing ratio was calculated from the following measured 
Fig. 6 Anomaly composites of daily 500-hPa geopotential height field with respect to 5,400 gpm (NNR). a, b Composites associated with the 95th percentiles of mean diurnal and nocturnal values at $40 \mathrm{~m}$. c, d Composites associated with the 5 th percentiles of mean diurnal and nocturnal values at $40 \mathrm{~m}$. e, f Difference fields (maximaminima). Solid (dashed) lines indicate positive (negative) contours drawn every $50 \mathrm{gpm}$ (20 gpm for $\mathbf{e , ~ f ) ; ~ z e r o ~ c o n t o u r s ~}$ omitted. In a-d, red (blue) contours every $5 \%$ indicate anomalies over (below) $75 \%$ ( $25 \%$ ) of the adjusted normal distribution for this variable at each grid point. A black cross indicates the location of the SGO metmast
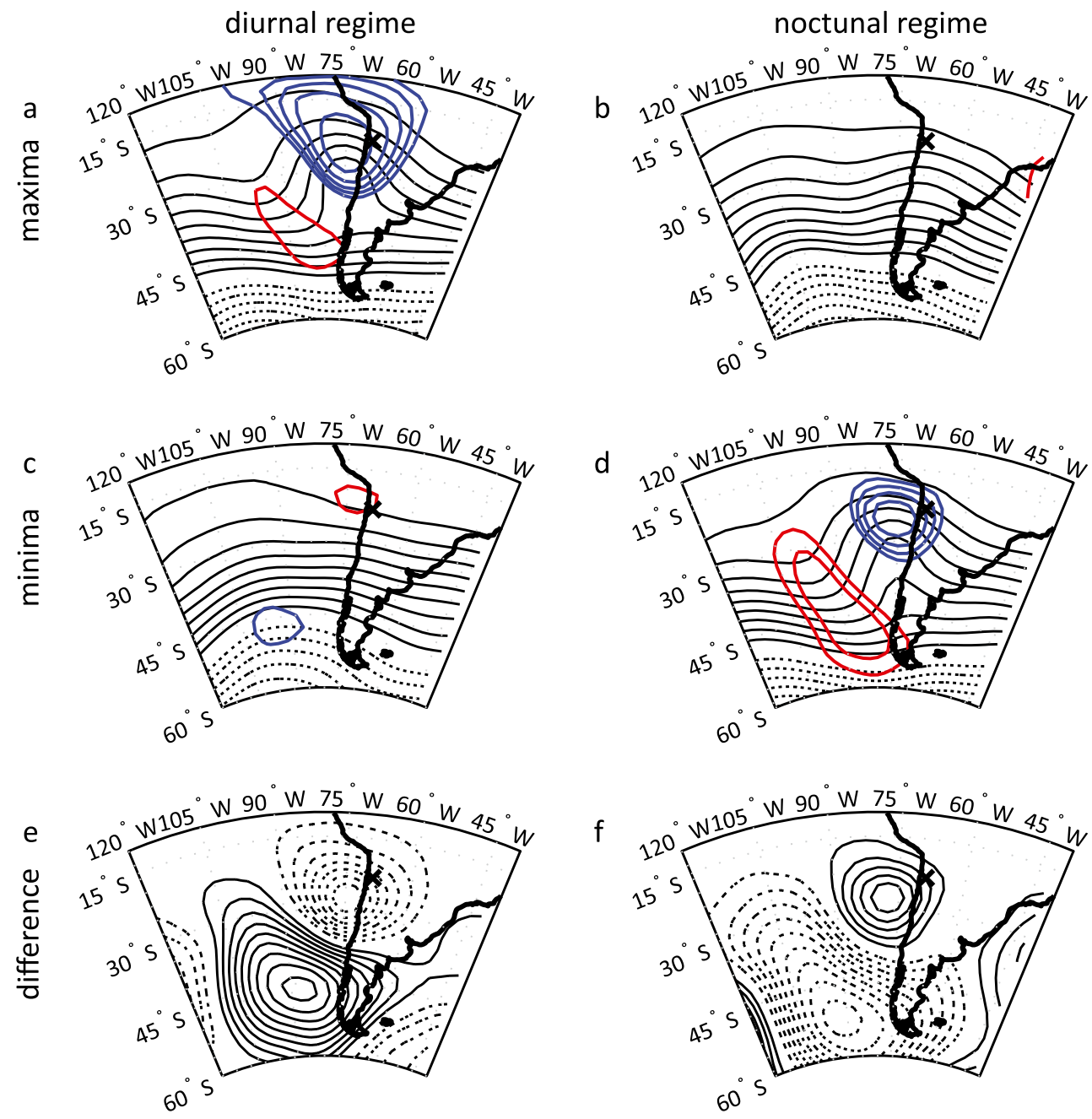

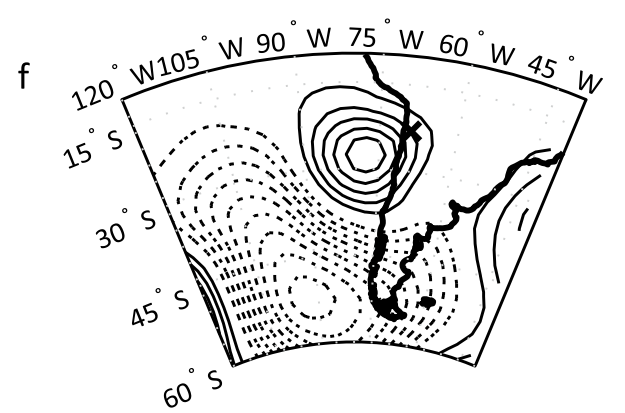

variables: air temperature at $2 \mathrm{~m}$, air pressure at $5 \mathrm{~m}$, and relative humidity at $2 \mathrm{~m}$. There is a positive correlation coefficient $\left(r=0.33^{*}, r^{2}=0.11\right)$ during the diurnal regime, which may be again a consequence of the advection of air masses from the Pacific Ocean, with more humid and colder air reaching the study site during strong wind events. The significant negative correlation during the nocturnal regime $(r=$ $-0.67^{*}, r^{2}=0.44$ ) could also be, at least partly, a consequence of the boundary layer mixing.

\section{Short-term predictability using the GFS model}

\subsection{Direct model verification}

GFS is a numerical weather prediction (NWP) model that has been developed by the US National Oceanographic and Atmospheric Administration (NOAA) offering forecasts of partly free access. It is initialized four times daily, with a maximum temporal horizon of 16 days $(384 \mathrm{~h})$. Within the first 7.5 days $(192 \mathrm{~h})$, it has a T574 spectral horizontal resolution $(\sim 27 \mathrm{~km})$, which reduces to T190 $(\sim 84 \mathrm{~km})$ afterward. Vertically, it has a pressure-sigma hybrid coordinate system. The temporal resolution of the forecasts is $3 \mathrm{~h}$ for the first 180 and $12 \mathrm{~h}$ until the end of the runs. A major actualization of the model was implemented on July 28, 2010, which lies in the middle of our study period. Among the most relevant introduced changes are a higher horizontal resolution (previously, it was T382, i.e., $\sim 35 \mathrm{~km}$ ) and a major physics upgrade (e.g., concerning radiation and clouds, boundary layer scheme, and convection schemes). After having checked the data, we conclude that, apart from surface pressure, this modification does not significantly impact the variables used in our analysis. Thus, we will use forecasts of the cycle initialized at $00 \mathrm{Z}$ of surface variables u-wind, v-wind, and wind speed at $10 \mathrm{~m}$ and the following column variables: $\mathrm{u}$ wind, v-wind, wind speed, temperature, geopotential height, and absolute vorticity at 1,000, 950, 900, 850, 800, 700, 600, 500,400 , and $300 \mathrm{hPa}$. Model time series corresponding to the SGO mast data have been calculated by linearly interpolating its four surrounding grid points, weighting them inversely to their corresponding distances to the site. 


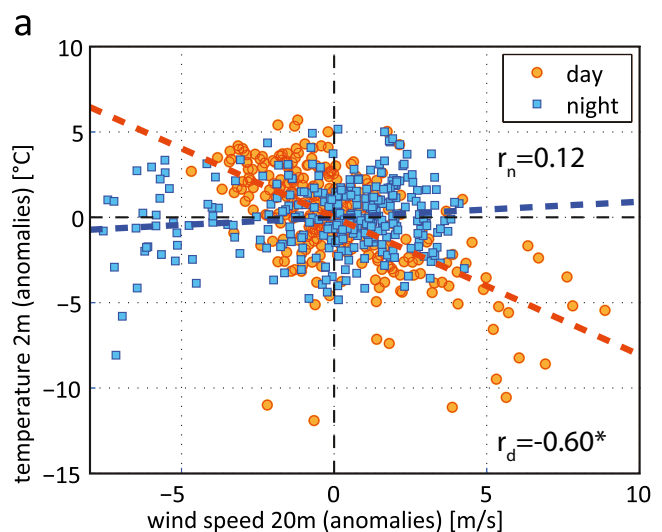

b

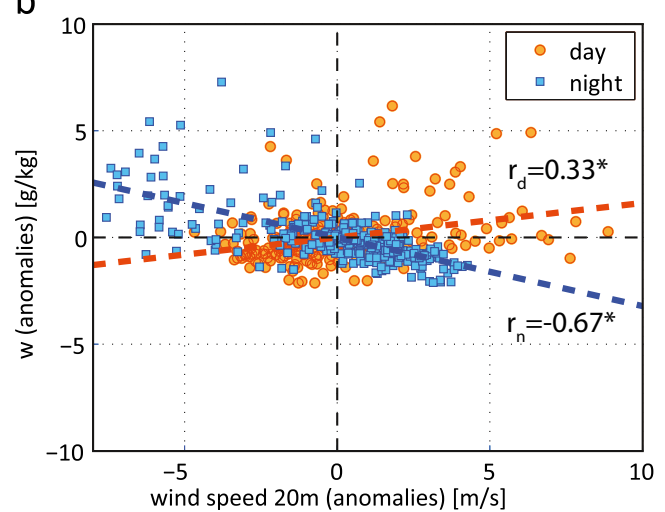

Fig. 7 Scatterplots of mean daily anomalies (after detrending and subtracting the annual cycle) of a 20-m wind speed and 2-m temperature and $\mathbf{b} 20-\mathrm{m}$ wind speed and surface water vapor mixing ratio during diurnal (orange) and nocturnal (light blue) regimes. Correlation values are indicated; the asterisk next to the number denotes statistical significance at $95 \%$

As commented in Sect. 1, we are aware of the limits imposed by assessing a local thermally driven wind system over complex topography by means of a global model. In this context, Werth and Garrett (2010) documented the magnitude of surface meteorology errors of the GFS model by comparing its forecasts with observations. In general, large errors were found in mountain regions and in areas of large topographic contrast, as is the case of the Andes next to the Atacama Desert. For wind speed at $10 \mathrm{~m}$ and at global scale, that study found a mean annual cycle of root-mean-squared error (RMSE) between 2 and $3 \mathrm{~m} / \mathrm{s}$, with a higher accuracy of the analysis than that of the 18- and 36-h forecasts. The model bias, found to be a strong driver of the annual cycle of RMSE, tends to be positive, i.e., model winds are in general too fast. In this sense, Sandu et al. (2013, and references therein) state that operational NWP models have a worse representation of stable boundary layer features (such as underestimated depth and weak low level jets) than research models. Sandu et al. (2013) showed that these drawbacks can be improved in the ECMWF IFS model by using a less diffusive turbulence scheme than the one used in its actual configuration. The better representation of features such as boundary layer winds, however, deteriorates the large-scale flow of the model and near-surface temperatures, which demonstrates the need of improvements also in other model aspects in order to enhance the skill of NWP models.

Nevertheless, the ability of GFS to reproduce the atmospheric conditions over the measurement site can be partly evaluated by the model daily cycles (Fig. 8a). We compare the 80-m wind speed observations, a level of interest concerning hub-height of wind turbines, with GFS forecasted values at $800 \mathrm{hPa}$ (solid curves), the pressure level closest to the location of the meteorological mast. We note that the bimodal cycle (with peaks in the diurnal and nocturnal regimes) is resolved by the model. However, it underestimates the observed magnitude in all forecast horizons. This issue is particularly pronounced during the night, when the intensity of the forecasted drainage wind is only $\sim 60 \%$ that of the measured wind speed. This bias is mostly caused by considerable discrepancies between forecasted and observed zonal components of the wind (dashed curves). The wind rose at $800 \mathrm{hPa}$ (not shown) reveals the same phenomenon: The GFS nocturnal easterly drainage wind, although well resolved in terms of direction, is weak compared to observations at $60 \mathrm{~m}$ (the only level with wind direction measurements). In contrast, the forecast wind at $700 \mathrm{hPa}$ (not shown) blows mainly from $\mathrm{NW}$ in both regimes, and no wind direction change is observed in between.

Furthermore, we assess the mean variance fraction of observed wind that is explained by the model forecasts within the first $72 \mathrm{~h}$ by means of the coefficient of determination $\left(r^{2}\right)$ for every time horizon (Fig. 8b). As possible variables for assessing the skill of the raw GPS forecast against observed $80-\mathrm{m}$ wind speed values, we selected model wind speed at $10 \mathrm{~m}, 800 \mathrm{hPa}$, and $700 \mathrm{hPa}$. Again, both nocturnal and diurnal regimes are clearly depicted in this measure by all variables. GFS wind speeds at $10 \mathrm{~m}$ and $800 \mathrm{hPa}$ show similar skill, with the latter one scoring slightly better for some time horizons than the first one $(\mathrm{T}+012, \mathrm{~T}+036$ and $\mathrm{T}+060)$. Considering these two variables and beyond the fact that a mean decrease of $r^{2}$ with time is noticeable, the most striking feature we observe is a better correspondence between forecasts and observations during the diurnal regime than during the nocturnal one and almost no correlation during the diurnalnocturnal transitions. On the other hand, forecast values at $700 \mathrm{hPa}$, which correspond to northwesterly wind at all time horizons, show skill only during the diurnal regime and do not correlate at all with observations during nighttime, when the drainage wind develops. Hence, we will use forecasted wind speed values at $800 \mathrm{hPa}$ as a benchmark for our postprocessing methodology.

Considering the fact that GFS wind speed forecast skill notably varies depending on whether the forecast horizon lies in the diurnal or in the nocturnal regime (Fig. 8a, b), it is interesting to explore to what extent the correlation 
Fig. 8 a Mean diurnal cycles of observed wind speed and zonal wind at $80 \mathrm{~m}$ (70-min running means, black curves) and forecasted values at $800 \mathrm{hPa}$ (orange curves). b Coefficient of determination $\left(r^{2}\right)$ between observed wind speed at $80 \mathrm{~m}$ and forecasted values at $10 \mathrm{~m}$ (red dashed curve), $800 \mathrm{hPa}$ (orange curve), and $700 \mathrm{hPa}$ (black dashed curve). c, d RMSE and bias of forecasted wind speed values at $800 \mathrm{hPa}$ against observations at $80 \mathrm{~m}$ : GFS raw values for 2010 (dashed black curve) and 2011 (dashed orange curve), 2010 training period (May 17, 2010-September 16, 2010, continuous black curve), and 2011 evaluation period (May 9, 2011-September 30, 2011, continuous orange curve)

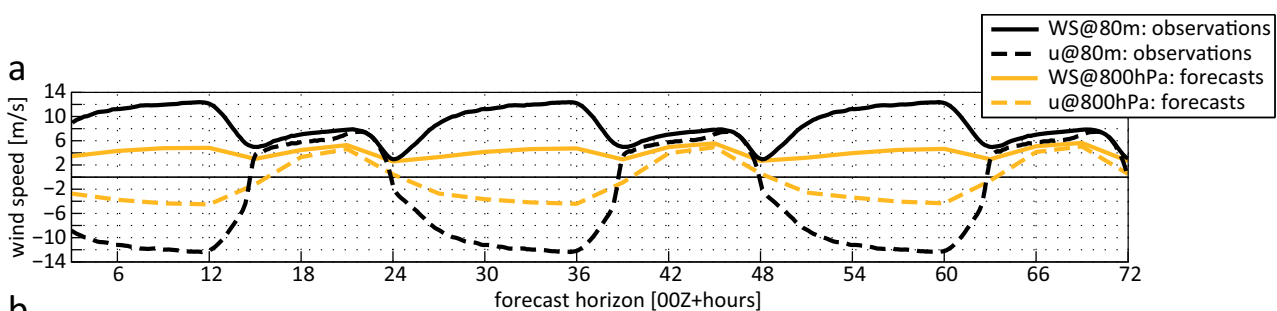

b

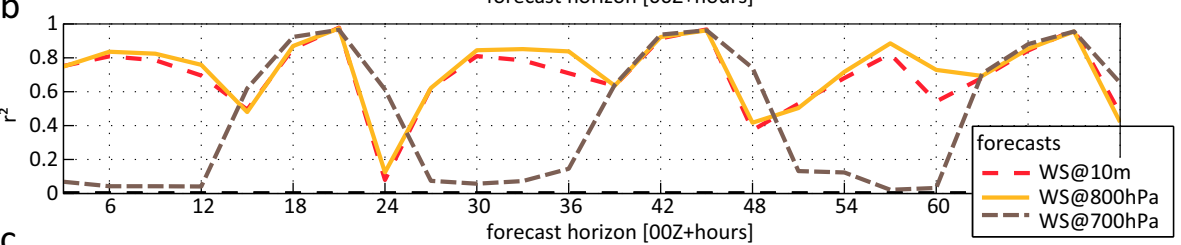

C

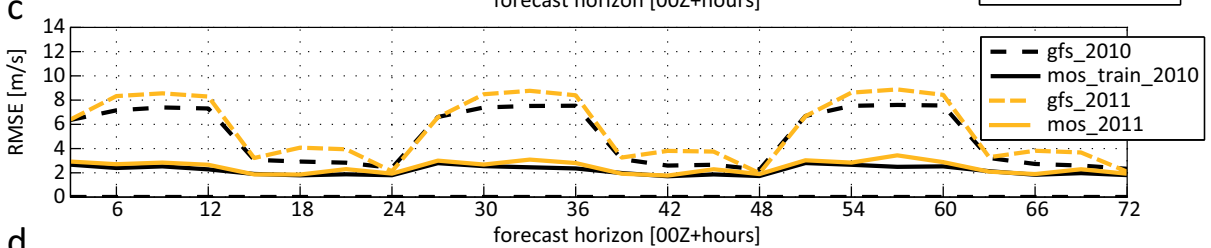

d

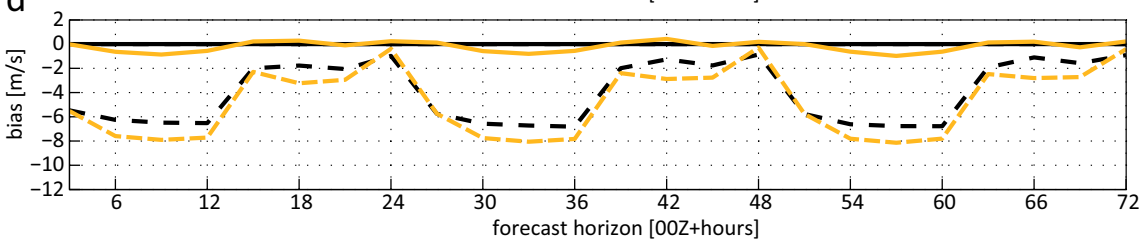

between forecasted atmospheric variables at different levels and wind speed observations at $80 \mathrm{~m}$ (i.e., the model skill) varies as a function of the time horizon of the forecast. Hence, we explore the correlation between a predictor base consisting of several forecast variables and the observed wind speed at $80 \mathrm{~m}$ during a training period in 2010 , spanning from May 17 to September 16. We use a Model Output Statistics (MOS, Glahn and Lowry (1972)) methodology to regress these observations on the variables that constitute our predictor base. Since it is actually $r^{2}$ that reflects the variance fraction explained by each predictor, it is important to emphasize that highly negatively correlated coefficients are just as valuable for the predictor base as highly positively correlated ones.

For simplicity, two forecast horizons from each regime have been selected to discuss our approach: $\mathrm{T}+006$ (nocturnal regime, 06Z/2 a.m. LT) and $\mathrm{T}+018$ (diurnal regime, 18Z/ 2 p.m. LT). For the diurnal regime, wind speed at $80 \mathrm{~m}$ positively correlates at all levels with wind speed and uwind. We find negative correlation coefficients associated to $\mathrm{v}$-wind and temperature (all levels), geopotential height (700 $300 \mathrm{hPa}$ ), and absolute vorticity (below $700 \mathrm{hPa}$ ). The highest correlation coefficients are found for the meridional component of wind speed at $400 \mathrm{hPa}\left(r=-0.75^{*}, r^{2}=0.57\right)$. These results show physical consistency and agree with the description of the observations, since they account for the diurnal NW flow over SGO, associated with humid and cold advection from the Pacific Ocean, which intensifies with upper-level troughs.

On the other hand, observed wind speed at $80 \mathrm{~m}$ during the nocturnal regime shows positive correlation coefficients with v-wind (all levels), temperature (700$400 \mathrm{hPa}$ ), upper-level geopotential height (700-300 hPa), and low-level wind speed (below $800 \mathrm{hPa}$ ). Negative correlation coefficients result when considering upper-level wind speed (700-300 hPa) and u-wind (all levels). The maximum absolute correlation coefficient is found for forecasted $\mathrm{u}$-wind at $400 \mathrm{hPa}\left(r=-0.75^{*}, r^{2}=0.56\right)$, well above the mast altitude. These results emphasize also the synoptic influence of upper-level atmospheric circulation in the modulation of the nocturnal local flow. As revealed by the observations and discussion in Sect. 3, the highest strength of the drainage flow is associated to a subtle and zonally uniform upper-level geopotential height gradient, that is, to a relatively weak synoptic disturbance. Furthermore, the nocturnal regime is characterized by a pronounced low-level easterly flow and somewhat warm advection (Fig. 7a), which agrees with the coefficients found for temperature. Particularly, as seen from the zonal component of the wind at $800 \mathrm{hPa}$, the direction of the nocturnal flow is well reproduced. Nevertheless, the positive correlation coefficients between forecasted wind speed at this level and the observations are weaker than those calculated for the diurnal regime, which results in a modest 
skill of the model during the nocturnal regime, consisting mostly of a bias.

\subsection{MOS adjustment of the GFS model}

Errors in NWP forecasts can be partly caused by limitations in computational resolution and quality of input data (Sweeney et al. 2013). In our case, discrepancies between forecast and observed cycles during the nocturnal regime could be a consequence of a poor model spatial resolution unable to represent the steep regional topography, which partly leads to the intense observed drainage winds. Systematic differences between GFS forecasts and observations, however, can be reduced by means of statistical post-processing methods, in particular the MOS methodology, which has been successfully applied and exhaustively addressed in the literature (Cheng and Steenburgh 2007; Sweeney et al. 2013).

In this study, we use a multiple linear regression of our predictand, the wind speed observations at $80 \mathrm{~m}$ (adapted as the 70-min running mean of the original 10-min averages) over a predictor base. To the initial three model surface predictors (u-wind, v-wind, and wind speed at $10 \mathrm{~m}$ ) and six column predictors (u-wind, v-wind, wind speed, temperature, geopotential height, and absolute vorticity), available at ten vertical pressure levels $(1,000,950,900,850,800,700,600$, 500,400 , and $300 \mathrm{hPa}$ ), we add four other variables: $80-\mathrm{m}$ wind speed observations from the previous day of the forecast initialization ( $24 \mathrm{~h}$ lagged, as a measure for possible persistence), two orthogonal sinusoidal functions of period equal to 1 year to adjust the annual cycle, and a constant that accounts for the bias. These 67 variables form a predictor base for the observed wind speed at $80 \mathrm{~m}$, which is different for each time horizon. Although the relevance of considering the thermal stratification of the atmosphere for regression purposes has been stressed in previous works, we do not include this parameter since it is linearly dependent with the existing predictors and does not improve our results, as proved by sensitivity tests (not shown).

As discussed before, the GFS model skill, as quantified by the RMSE at $800 \mathrm{hPa}$ (the closest model level to the metmast), shows a strong daily cycle instead of just a monotonic increase with time, as normally expected (Fig. 8c). Figure 8d clearly shows that the RMSE is greatly caused by the bias, which constitutes the main error source of the model. Considering these facts, we apply an individual MOS approach for each forecast horizon on its corresponding predictor base, previously dimensionally reduced via principal component analysis (PCA). This technique allows the reduction of a group of variables into a more compact one, formed by linear combinations of them. This procedure is particularly useful when implemented on atmospheric fields, which are usually highly correlated (Wilks 2006). In this study, PCA has been applied on the correlation matrix calculated from standardized variables, in order to avoid scale distortion due to different units. Through PCA, we obtain general relationships between the predictors and the predictand and hinder over-adjustment of the regression constants. These constants, which are calculated for the training period and, as expected, vary for every time horizon, are subsequently used to post-process the forecast. The final aim of the methodology is that this postprocessing be done in an operational manner.

Evidently, results depend on whether the training period is representative enough of a broad spectrum of weather patterns, and thus, long series are very valuable. Although data availability in our case is restricted, we attempt a preliminary study of this aspect by means of our 2 years of observations. Thus, we will use 2010 as a training period to calculate regression constants and 2011 as an evaluation period to assess our results. Two aspects to consider concerning this PCA regression are as follows: (a) the determination of the length of the training period and (b) the number of empirical orthogonal functions to retain in the reduced predictor base. For this purpose, we carried out sensitivity analysis by comparing the original raw GFS forecasts and the improvement reached by diverse MOS configurations. Concerning the training period length, we explored the results obtained for the evaluation period May 9 to September 30, 2011 using different training intervals in 2010, with a fixed ending date on September 16, 2010. As expected, RMSE decreases with longer training periods, since the observations become more representative of diverse atmospheric situations. Mainly restricted by data availability, we finally selected a 4-month training period, starting on May 17, 2010. With this parameter fixed, we then explored the RMSE reduction as a function of retained PCs. We conclude that the minimum RMSE value obtained through the MOS approach for the 2011 evaluation period is achieved by varying numbers of retained empirical orthogonal functions (EOFs) for each forecast time horizon. For simplicity, however, we decided to use the first five EOFs in the final base for every time horizon, which preserve more than $80 \%$ of the variance of the original predictor base for each case. It is worth noting that RMSE values do not necessarily decrease with increasing retained EOFs in the predictor base. That is, for every time horizon there is an optimal EOF configuration which leads to the minimum RMSE value. Although the increase in RMSE due to adding or removing an EOFs from this optimal base is subtle, the RMSE smoothly increases by adding more EOFs to the optimal configuration until it suddenly explodes at around 50 EOFs. We interpret this result as an overfitting of the training period. In other words, if the predictor base turns too complex, the regression constants calculated for the training period lose representativity for the evaluation period.

The MOS application over SGO is illustrated in Fig. 9 as time series for part of the evaluation period (August 2011, all time horizons). As already described, the dimension-reduced 
Fig. 9 MOS adjustment of GFS forecasts at SGO during August 2011 (within the evaluation period): time series of observed wind speed at $80 \mathrm{~m}$ (70-min running means, blue), raw GFS forecasts for wind speed at $800 \mathrm{hPa}$ (green), and adjusted MOS values (red). Note that all forecast horizons are considered, and thus, three different forecasts are available for every hour
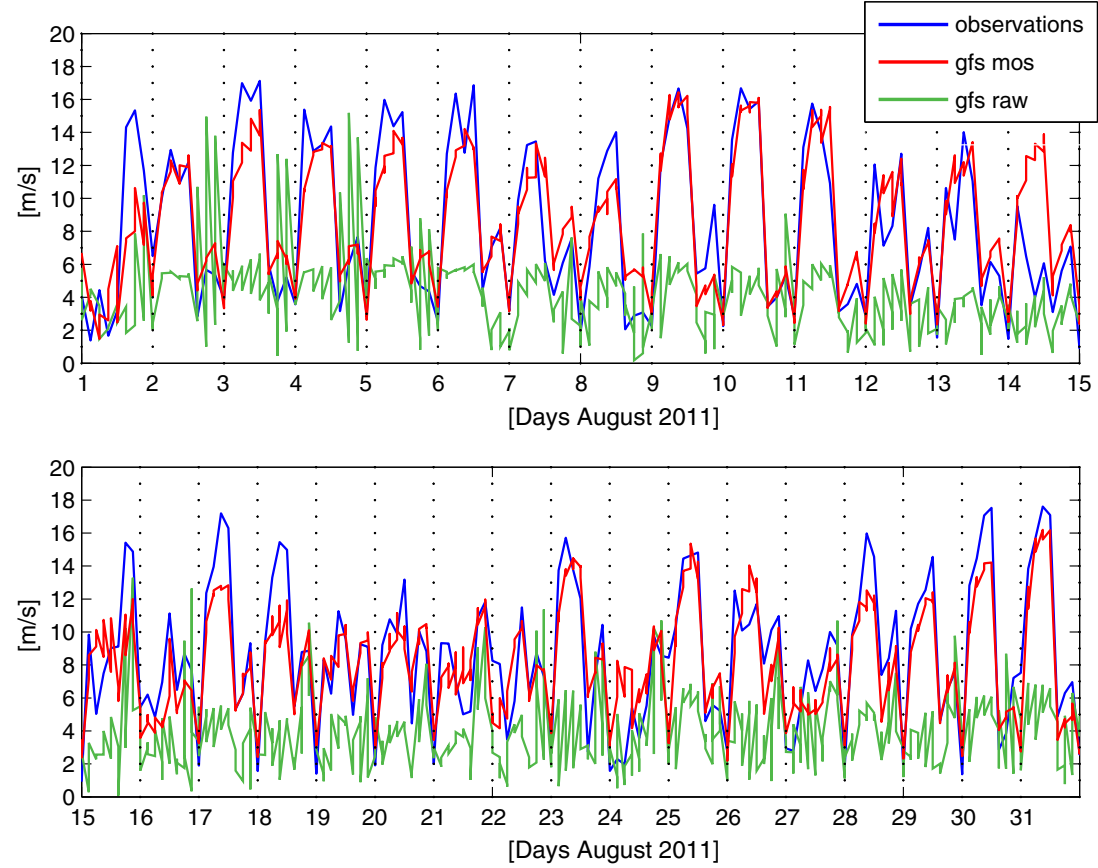

predictor base, calculated from the model forecasted variables, is linearly adjusted through the constants calculated during the 2010 training period, yielding the post-processed MOS forecast (red). We note that this output matches better the smoothed $80-\mathrm{m}$ observations (blue) than the raw $800 \mathrm{hPa}$ forecasted wind speed (green). It is clear that raw GFS forecasts at $800 \mathrm{hPa}$ permanently underestimate observed values. Here, we show that this bias can substantially be reduced by means of the MOS approach. Considering the evaluation period in 2011, the average mean absolute windspeed forecast error for the diurnal period $(\mathrm{T}+015, \mathrm{~T}+018, \mathrm{~T}+021, \mathrm{~T}+$ 024) was reduced from $-35.4 \%$ to $3.7 \%$, whereas for the nocturnal period $(\mathrm{T}+003, \mathrm{~T}+006, \mathrm{~T}+009, \mathrm{~T}+012)$ it was improved from $-63.1 \%$ to $-4.3 \%$. That is, by applying this technique, the amplitudes of the intra-daily diurnal and nocturnal cycles are adjusted, and also the inter-daily (synoptic) variability is satisfactorily captured. MOS post-processed forecasts still tend, however, to underestimate the observations, as shown for selected time horizons in the scatterplots of Fig. 10. Again, we observe here that post-processed results better correspond to the 1:1 line with observations than the raw forecasted wind speed at $800 \mathrm{hPa}$. From this figure, it is clear that the MOS procedure adjusts to the mean conditions during the training period and, as expected, does not show a good skill when dealing with extreme events.

Finally, we comment our results considering the same time horizons as in the previous section, 06Z and 18Z (Fig. 10 and Table 1). During the diurnal regime (18Z), we find relatively low RMSE values. By applying the MOS, we get an RMSE reduction of $55 \%$ (from 4.1 to $1.9 \mathrm{~m} / \mathrm{s}$ ) and a mean absolute error (MAE) reduction of $63 \%$ (from 3.5 to $1.3 \mathrm{~m} / \mathrm{s}$ ). During this time horizon, the first two EOFs from the predictor base explain 56.8 and $11.1 \%$ of the variance of the original predictor base, respectively. Moreover, for this time horizon and during the evaluation period, the first two (five) EOFs from the predictor base account for $49.8 \%(52.7 \%)$ of the total variance of the wind speed observations at $80 \mathrm{~m}$, as measured by the cumulative sum of $r^{2}$. As a general observation for all time horizons, we note that the first EOFs of the predictor base, which explain the highest fractions of its internal variability, also have the strongest relationship to the wind speed recorded at $80 \mathrm{~m}$. In addition, we can interpret the physical meaning of the retained EOFs by analyzing the absolute values ("weights") of the coefficients of each original variable in them (i.e., the projection of the original variables onto the EOFs). Thus, the highest-weighted variables are the ones which build up the major part of the EOF and hence of the predictor base variability at a given forecast horizon. In Table 2, we list the variables whose absolute coefficients are greater than 1 in the nomalized EOFs. In EOF1, both the variables most represented as well as their corresponding signs depict our finding discussed previously: Diurnal wind speed maxima are caused by negative anomalies in mid-level geopotential height centered to the west of the site (Fig. 6), a pattern that is associated with enhanced wind speed and cold advection in the NW-SE direction, as also depicted by observational data (Fig. 7a).

In contrast, higher RMSE values are found during the nocturnal regime (06Z). In this case, the MOS postprocessing allows us to reduce the RMSE by $68 \%$ (from 8.3 to $2.7 \mathrm{~m} / \mathrm{s}$ ) and the MAE by $73 \%$ (from 7.7 to $2.1 \mathrm{~m} / \mathrm{s}$ ). The first two nocturnal EOFs explain 37.3 and $21.6 \%$ of the 
Fig. 10 Scatterplots of $80 \mathrm{~m}$ observed wind speed (70-min running means) against GFS $800 \mathrm{hPa}$ forecasted wind speed during the training period (May 17, 2010-September 16, 2010, left) and the evaluation period (May 9, 2010-September 30, 2011, right). Original forecast values are shown in green, and MOS-adjusted values are shown in red. The diurnal regime is represented by $\mathrm{T}+006(2 \mathrm{a} . \mathrm{m}$ local time) and the nocturnal regime $\mathrm{T}+018$ ( 2 p.m. local time). Corresponding statistics are shown in Table 1
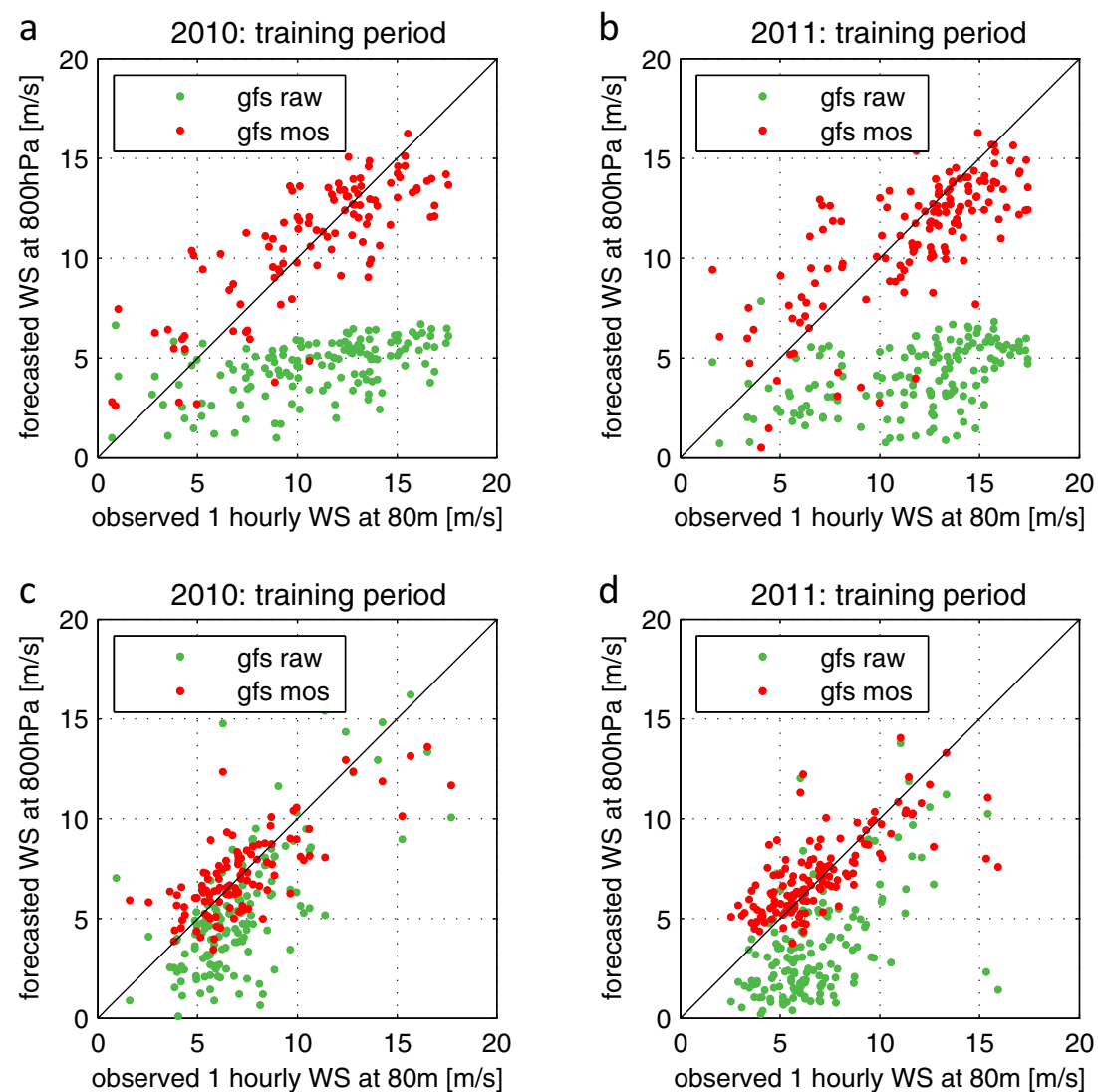

variance of the original predictor base, respectively. Besides, for this time horizon and during the evaluation period, the first two (five) EOFs from the predictor base account for $50.5 \%$ $(61.6 \%)$ of the total variance of the wind speed measurements at $80 \mathrm{~m}$, as revealed by the cumulative sum of $r^{2}$. The variables with the highest coefficients in the first two EOFs are shown in Table 2. Again, we observe that the physical relationships found in the first part of our study for the variability of the nocturnal flow are reflected in the variables retained in the predictor base. Specifically, we note that EOF1 consistently exhibits (with inverse sign) the atmospheric configuration leading to nocturnal minima (Fig. 6): negative mid-level geopotential height anomalies, positive zonal wind at all levels, and negative meridional winds at low and mid-levels, centered to the west of the site.

\section{Conclusions}

Based on the analysis of 2 years of instrumental data, we have presented novel aspects of the wind regime over Sierra Gorda in the Atacama Desert during the extended austral winter (MJJAS). Daily cycles of different variables reveal the distinction between a diurnal regime (1 p.m., 6 p.m.), with northwesterly flow and maximum mean wind speed of $8 \mathrm{~m} /$

Table 1 Statistics of forecasted versus observed wind speed values (see Fig. 10): root-mean-square error (RMSE), mean absolute error (MAE), and bias Nocturnal regime, $\mathrm{T}+006$

Diurnal regime, $\mathrm{T}+018$

\begin{tabular}{lllll}
\hline & 2010 (training period) & 2011 (evaluation period) & 2010 (training period) & 2011 (evaluation period) \\
RMSE raw & 7.2 & 8.3 & 2.9 & 4.1 \\
RMSE mos & 2.4 & 2.7 & 1.8 & 1.9 \\
MAE raw & 6.5 & 7.7 & 2.3 & 3.5 \\
MAE mos & 1.9 & 2.1 & 1.4 & 1.3 \\
BIAS raw & -6.3 & -7.6 & -1.8 & -3.3 \\
BIAS mos & 0.0 & -0.6 & 0.0 & 0.3 \\
\hline
\end{tabular}


Table 2 Variables showing the highest coefficients in the two first normalized EOFs of the PCA-reduced predictor base (five EOFs) for forecast horizons within the diurnal $(\mathrm{T}+018,18 \mathrm{Z})$ and the nocturnal $(\mathrm{T}+006,06 \mathrm{Z})$ regimes

\begin{tabular}{|c|c|c|c|c|}
\hline \multicolumn{3}{|c|}{ Diurnal regime, $\mathrm{T}+018: \mathrm{EOF} 1$ (EOF2) } & \multicolumn{2}{|c|}{ Nocturnal regime, $\mathrm{T}+006$ : EOF1 (EOF2) } \\
\hline Variable & Levels & Sign & Levels & Sign \\
\hline $\mathrm{u}$-wind at $10 \mathrm{~m}$ & $10 \mathrm{~m}(-)$ & Pos. (-) & $10 \mathrm{~m}(10 \mathrm{~m})$ & Neg. (neg.) \\
\hline $\mathrm{v}$-wind at $10 \mathrm{~m}$ & $10 \mathrm{~m}(-)$ & Neg. $(-)$ & $10 \mathrm{~m}(-)$ & Pos. $(-)$ \\
\hline Wind speed at $10 \mathrm{~m}$ & $10 \mathrm{~m}(-)$ & Pos. $(-)$ & $-(10 \mathrm{~m})$ & - (Pos.) \\
\hline Zonal wind & $1,000-600 \mathrm{hPa}(-)$ & Pos. $(-)$ & $1,000-300 \mathrm{hPa}(1,000-800 \mathrm{hPa})$ & Neg. (pos.) \\
\hline Meridional wind & $1,000-600 \mathrm{hPa}(-)$ & Neg. (-) & $1,000-600 \mathrm{hPa}(-)$ & Pos. (-) \\
\hline Wind speed & $1,000-500 \mathrm{hPa}(500-300 \mathrm{hPa})$ & Pos. (pos.) & $700-300 \mathrm{hPa}(1,000-800 \mathrm{hPa})$ & Neg. (neg.) \\
\hline Temperature & $1,000-500 \mathrm{hPa}(1,000-600 \mathrm{hPa})$ & Neg. (neg.) & $700-500 \mathrm{hPa}(1,000-800 \mathrm{hPa})$ & Pos. (pos.) \\
\hline Geopotential height & $700-300 \mathrm{hPa}(1,000-800 \mathrm{hPa})$ & Neg. (pos.) & $700-300 \mathrm{hPa}(-)$ & Pos. $(-)$ \\
\hline Absolute vorticity & $800-700 \mathrm{hPa}(600-400 \mathrm{hPa})$ & Pos. (neg.) & $-(800 \mathrm{hPa})$ & - (Pos.) \\
\hline Previous day observation & $-(80 \mathrm{~m})$ & $-($ Pos.) & $-(-)$ & $-(-)$ \\
\hline Sin & $-(-)$ & $-(-)$ & $-(-)$ & $-(-)$ \\
\hline Cos & $-(-)$ & $-(-)$ & $-(-)$ & $-(-)$ \\
\hline Constant & $-(-)$ & $-(-)$ & $-(-)$ & $-(-)$ \\
\hline
\end{tabular}

Only coefficients greater than 1 in module are shown

Pos, positive, Neg, negative

s, and a nocturnal regime (8 p.m., 9 a.m.), with predominant easterly flow and maximum mean speed of $13 \mathrm{~m} / \mathrm{s}$. These pronounced cycles are caused by the sloping regional topography, the local radiative balance, and the consequent formation and destruction of a nocturnal thermal inversion. The inter-daily variability of both regimes shows that corresponding extreme events are inversely correlated: High diurnal wind speed roughly coincide with low nocturnal wind speed and vice versa. Furthermore, we described the corresponding synoptic forcings that lead to such extreme events: While upperlevel troughs along the Pacific coast reinforce diurnal NW wind, mean undisturbed conditions allow the development of the nocturnal regime.

Additionally, in this study, we assessed the local predictability of wind speed at $80 \mathrm{~m}$ based on output from the GFS global model. Forecasted values at $800 \mathrm{hPa}$ (the closest level to the metmast) strongly underestimate the observations at $80 \mathrm{~m}$. Moreover, a pronounced model skill difference is observed between the diurnal and the nocturnal regimes, with better results observed for the former one. Although the model reproduces the easterly direction of the flow during night, the wind magnitude is significantly underpredicted. This is reflected in a strong daily cycle of the forecast RMSE, mostly caused by the bias. In order to reduce this error, a MOS approach was applied. It consists of a linear regression of the observations, calculated separately for every forecast horizon, on a multivariate predictor base previously dimensionally reduced via PCA. We selected an optimized configuration of this approach, considering 2010 as a training period and evaluating our results for 2011. As a result, we obtained a mean improvement of the MOS post-processed forecasts consisting in a negligible bias and an RMSE reduction of $68 \%(55 \%)$ for wind speeds verifying on $\mathrm{T}+006(\mathrm{~T}+018)$ during the nocturnal (diurnal) regime.

Our methodology reveals a simple way by which freely available GFS forecasts can be adapted to complex local circulation in northern Chile, where wind energy potential may be of interest. A positive aspect of this particular statistical post-processing technique is the relatively low computational effort required to apply it. On the other hand, the limitations imposed by our approach are in line with the findings of Werth and Garrett (2010), who concluded that although GFS is adequate for forecasting large-scale weather systems, it has problems when used to predict smaller-scale features of surface weather. Nevertheless, in the first part of this paper, we demonstrated that there are physical relationships between the regional synoptic forcing and the local thermally driven wind system. Thus, the combination of the forcing reproduced by the GFS model and the instrumental observations, which were the target of the MOS correction, led to the significant forecast improvements achieved in this study. Although absolute wind speed values and intra-daily and inter-daily variability are better represented after applying this methodology, the final RMSE values reached are still greater than those typically reported in the literature (e.g., Lange and Focken 2006; Sweeney et al. 2013) and thus seem to be not low enough for operational wind energy forecasting. For future research, we suggest the development of local highresolution models as a more promising option than attempting further statistical efforts based on data from global models. 
Present results, obtained by empirical post-processing of the GFS forecasts, are still useful, however, as a benchmark for assessing future work and allowing the assessment of the benefits of alternative approaches.

Acknowledgments Funding for this research was provided by a cooperation agreement between the University of Chile and the Chilean Ministry of Energy under Exempt Decree 249 of 2013 . The measurement campaign in northern Chile was carried out by programs of the Chilean Ministry of Energy, with partial support from the German GIZ Agency (Deutsche Gesellschaft für Internationale Zusammenarbeit $\mathrm{GmbH}$ ). NCEP Reanalysis data provided by the NOAA/OAR/ESRL PSD, Boulder, Colorado, USA, from their Web site (http://www.esrl.noaa.gov/psd/). GFS data was obtained from the USA NOAA National Climatic Data Center (http://www.ncdc.noaa.gov/). MJC acknowledges ForWind (Universität Oldenburg, Germany), in particular Dr. Thomas I. Petroliagis, for the experience gained during a research internship financed by "Programa en Energías" (CONICYT-Chile). This paper was greatly improved by the comments and suggestions of two anonymous reviewers.

\section{References}

Bretherton CS, Widmann M, Dymnikov VP et al (1999) The effective number of spatial degrees of freedom of a time-varying field. J Clim 12:1990-2009. doi:10.1175/1520-0442(1999) 012<1990:TENOSD $>2.0 . \mathrm{CO} ; 2$

Cheng WYY, Steenburgh WJ (2007) Strengths and weaknesses of MOS, running-mean bias removal, and Kalman filter techniques for improving model forecasts over the Western United States. Weather Forecast 22:1304-1318. doi:10.1175/2007WAF2006084.1

Comisión Nacional de Energía de Chile (CNE) (2011) Capacidad instalada por sistema eléctrico nacional. http://antiguo.cne.cl/ cnewww/export/sites/default/06_Estadisticas/Documentos/ capacidad instalada_de generacion.x 1 s. Accessed 22 Aug 2013

Garreaud RD (2009) The Andes climate and weather. Adv Geosci 22:311. doi:10.5194/adgeo-22-3-2009

Garreaud RD, Falvey M (2009) The coastal winds off western subtropical South America in future climate scenarios. Int J Climatol 29:543554. doi:10.1002/joc. 1716

Garreaud R, Rutllant J (2003) Coastal lows along the Subtropical West Coast of South America: numerical simulation of a typical case. Mon Weather Rev 131:891-908. doi:10.1175/1520-0493(2003) $131<0891$ :CLATSW $>2.0$. CO;2

Garreaud RD, Molina A, Farias M (2010) Andean uplift, ocean cooling and Atacama hyperaridity: a climate modeling perspective. Earth Planet Sci Lett 292:39-50. doi:10.1016/j.epsl.2010. 01.017

Glahn HR, Lowry DA (1972) The use of model output statistics (MOS) in objective weather forecasting. J Appl Meteorol 11:1203-1211. doi: 10.1175/1520-0450(1972)011<1203:TUOMOS >2.0.CO;2
Hall S, Román R, Cuevas F, Sánchez P (2009) ¿Se necesitan represas en la Patagonia? Un análisis del futuro energético chileno. 88

Kalnay E, Kanamitsu M, Kistler R et al (1996) The NCEP/NCAR 40year reanalysis project. Bull Am Meteorol Soc 77:437-471. doi:10. 1175/1520-0477(1996)077<0437:TNYRP > 2.0.CO;2

Kalthoff N, Bischoff-Gauß I, Fiebig-Wittmaack M et al (2002) Mesoscale wind regimes in Chile at 30 ${ }^{\circ} \mathrm{S}$. J Appl Meteorol 41:953-970. doi:10. 1175/1520-0450(2002)041<0953:MWRICA >2.0.CO;2

Lange M, Focken U (2006) Assessment of wind speed dependent prediction error. Phys. Approach to Short-Term Wind Power Predict. SE - 8. Springer Berlin Heidelberg, 115-133

Meyer TP (2011) Staatliche Liegenschaften für Projekte zur Stromerzeugung aus erneuerbaren Energien. http://www.giz.de/ Themen/de/27911.htm. Accessed 22 Aug 2013

Muñoz RC, Garreaud R (2005) Dynamics of the low-level jet off the West Coast of subtropical South America. Mon Weather Rev 133:36613677. doi:10.1175/MWR3074.1

Muñoz RC, Falvey MJ, Araya M, Jacques-Coper M (2013) Strong downvalley low-level jets over the Atacama Desert: observational characterization. J Appl Meteorol Climatol. doi:10.1175/JAMC-D-13063.1

Rahn DA, Garreaud RD, Rutllant JA (2011) The low-level atmospheric circulation near Tongoy Bay-Point Lengua de Vaca (Chilean Coast, $30^{\circ} \mathrm{S}$ ). Mon Weather Rev 139:3628-3647. doi:10.1175/MWR-D11-00059.1

Rutllant J, Ulriksen P (1979) Boundary-layer dynamics of the extremely arid northern part of Chile. Bound-Layer Meteorol 17:41-55. doi: 10.1007/BF00121936

Rutllant JA, Fuenzalida H, Aceituno P (2003) Climate dynamics along the arid northern coast of Chile: the 1997-1998 Dinámica del Clima de la Región de Antofagasta (DICLIMA) experiment. J Geophys Res Atmos 108:4538. doi:10.1029/2002JD003357

Rutllant JA, Muñoz RC, Garreaud RD (2013) Meteorological observations on the northern Chilean coast during VOCALS-REx. Atmos Chem Phys 13:3409-3422. doi:10.5194/acp-13-3409-2013

Sandu I, Beljaars A, Bechtold P et al (2013) Why is it so difficult to represent stably stratified conditions in numerical weather prediction (NWP) models? J Adv Model Earth Syst 5:117-133. doi:10.1002/ jame.20013

Schmidt D (1999) Das Extremklima der nordchilenischen Hochatacama unter besonderer Berucksichtigung der Hohengradienten. Dresdener, Dresdener Geogr Beiträge, p 122

Sweeney CP, Lynch P, Nolan P (2013) Reducing errors of wind speed forecasts by an optimal combination of post-processing methods. Meteorol Appl 20:32-40. doi:10.1002/met.294

Von Bremen L, Saleck N, Heinemann D (2007) Enhanced regional forecasting considering single wind farm distribution for upscaling. J Phys Conf Ser 75:12040

Werth D, Garrett A (2010) Patterns of land surface errors and biases in the global forecast system. Mon Weather Rev 139:1569-1582. doi:10. 1175/2010MWR3423.1

Whiteman CD (2000) Mountain meteorology: fundamentals and applications, 1 st ed. 355

Wilks D (2006) Statistical methods in the atmospheric sciences, 2nd ed. International Geophysics Series, 2nd Editio. 627 